\title{
STRUCTURED EDUCATION FOR SUSTAINABLE EMPLOYMENT: TECHNOLOGY ENABLED QUEUEING THEORY APPLICATIONS
}

\author{
Bhaskar GARIMELLA*, Sandeep SHENOY**, \\ Rashmi Yogesh PAI***, Rishali SHETTY**** \\ Department of Commerce, MAHE Manipal University, Manipal, Karnataka, INDIA \\ e-mail: $\{*$ gbn.rao, $* *$ sandeep.shenoy, $* * *$ rashmi.pai $\} @$ manipal.edu \\ ****e-mail: rishali.shetty@gmail.com
}

\begin{abstract}
Unemployment is a serious challenge that has been rising day by day. Skill development and creation of employment opportunities are key factors to address youth unemployment. This study emphasizes on the need for job-oriented education and to link education to employment. This study derives a mathematical model and tests the same using live university hiring data and attempts to integrate the three stakeholders, employers, education providers, and the young, each of whom have a unique approach, expectation, and understanding of the paradigm. Novel methodology inclusive of empirical evidence-based integration of objective fulfillment drafted into institutional pedagogy can help increase the success rate of education to employment from an Indian context especially Indian girls and women. The study outlines specific aspects of analytical intervention in this regard and focuses on systematic training programs exclusively for vocational and skills amelioration executed to address this multidimensional challenge by adopting easily implementable software methodologies that are more easily implementable over a wide area network or an Internet-based application engine powered by information communication technology.
\end{abstract}

Keywords: Sustainable Employment, Information Communication Technology, Queueing Theory Vocational Skills, Employability, Gender Studies, University Curriculum.

JEL: I21, O15, E24, C6, D83.

\section{Introduction}

The burgeoning population, factors of employability, robust education mechanism, and sustainable employment avenues are intricately connected. Improved education levels combined with acceptable living conditions are very powerful constructs that impact employment levels. Livelihoods enablement and access to employment are prime conditions for both economic and social securities (Mishra, et al., 2016).

The past five decades are evidence enough that the trodden path of Indian education has fumbled and far beyond success in terms of ensuring education output from a graduate level is satisfactory in the employment market, with one theme dominating all others (Dhongde, 2017), there is no clearly defined and tenured track in this paradigm. This study seeks to work on the track of education to employment from an Indian perspective.
India's workforce having surpassed the 500 million approximately in 2016 shall extend over at the rate of 16-18\% biannually for the next decade (Fernandez \& Kambhampati, 2017). The study seeks to understand the fundamental increase in projection of a perceived.

How ICT (information and communications technologies) can better orient the unique Indian scenario in terms of availability of trained and skilled persons, dynamic job creation by various projects, creation of a proposed pool (large) of trained resources, certified vocational blue-collared industrial worker pool, increased educational resources, and improved percentages of school goers.

The study has executed a systematic forecasting methodically that analyzed based on these variables the yield and effectiveness of published statistics, that is, India's employable population will grow by $60-70.5$ lakhs every year during the next 10 years, that is, 2017-2027. 


\subsection{Research objectives}

- Availability of skilled workforce is imperative from a business perspective and employability is an important variable from a student's perspective. Choice-based and multidimensional vocational education pursued by students seldom meets the specific skill requirement of large, medium, and small industries. This study seeks to ascertain the reason for scarcity of skilled workers at different occupational levels.

- An academic attempt to analyze student's (unemployed) skill variables with that of the employment opportunities presented by corporates, inherent mismatch(s) can be classified into parameters viz., cyclical, spatial, and structural. This study attempts to peruse and learn about the mismatch of demand and supply in the employment market from these parametric perspectives.

- Developing economies tend to rely on the manufacturing sector to enable growth. This study seeks to understand the adopted training methodology (ICT) for heterogeneous jobs and workers with diverse sets of skills and knowledge in the vocational market where information flow is a disarray.

\subsection{Literature review}

\section{- National Perspective}

ICT and sustainable development aspects in institutes of higher education around the globe need to rework their objectives (Landers \& Danes, 2016) in terms of pedagogy delivery systems and general living of students on campus (Bussemakers, et al., 2017). ICT enablement is an important function of higher quality of classroom delivery in a systematic method. It connects the policy initiatives to the education leaders who design seamless education methodologies (Brewer, et al., 2016), (Fatma \& Rahman, 2016) and (Fahey, et al., 2016).

\section{- International Perspective}

This research critically illustrates the general execution of higher education and its impact on employability in the eastern parts of Asia (Fernandez \& Kambhampati, 2017). This article applies social parameters as access to education issues and discusses predominant issues from an Asian context (Bose, 2017), (Mehrotra \& Parida, 2017).

Over the past two decades, European education market has witnessed rapid growth yielding in the flexibility to reach-out (Sahai, 2016) and acts as a partial tailored program that meets the objectives of both the industry and students. In Table 1, key variables as discussed in the literature review are presented for reference.

Table 1 . Key variables

(Source: Own study - compiled from library and academic repositories)

\begin{tabular}{|l|l|}
\hline \multicolumn{1}{|c|}{ Key Variable } & \multicolumn{1}{c|}{ Author } \\
\hline Organizational environment & Uma S. Kambhampati, 2017; Kars van Oosterhout, 2017 \\
\hline Finance-related pedagogy & Antonia Fernandez, 2017; Gerbert Kraaykamp, 2017 \\
\hline Strategic management pedagogy & Niels Spiering, 2017; Miet Maertens, 2017 \\
\hline Organization behavior & Nayana Bose, 2017 \\
\hline Industry interface & Eveline Smeets, 2017; Charles Fang Chin Cheng, 2017 \\
\hline Electives and credit transfers & Nobuya Haraguchi, 2017 \\
\hline Managing workplace Diversity & Santosh Mehrotra, 2017; Jajati K. Parida, 2017 \\
\hline Global business context & Armand Sim, 2017; Daniel Suryadarma, 2017; Asep Suryahadi, 2017 \\
\hline
\end{tabular}


A possible ICT oriented program aimed to yield in several aspects that comprise the enhancement of trainees' prospects (Woszczynski, et al., 2016) to broaden their vocational skills and equate and amalgamate all the conflicting opinions and the units that compete to elevate their expertise in conventional disciplines akin to "Business Management 1".

On these aspects, the study asserts that the variables presented in Table 2 can be considered for a business module training program as the approach and deployment standard and a beginner, an intermediate, and an advanced standard of delivery.

Table 2. Possible segregation and conceptualization of business studies delivery

(Source: Own study - compiled from library and academic repositories)

\begin{tabular}{|l|l|l|}
\hline \multicolumn{1}{|c|}{ Standard 1 } & \multicolumn{1}{|c|}{ Standard 2 } & \multicolumn{1}{c|}{ Standard 3 } \\
\hline Business proficiency & Employability development & Professional development \\
\hline Marketing dynamics & Business analysis and practice & Consultancy project \\
\hline $\begin{array}{l}\text { Business information and } \\
\text { management of organization }\end{array}$ & Operations management & Managing capability \\
\hline Economic awareness & Business decision making & Business strategy \\
\hline Organizational environment & Introduction to managerial finance & Managing in a mixed economy \\
\hline Business accounting & Social theory & Management of international business \\
\hline Business data analysis & Managing workplace diversity & $\begin{array}{l}\text { Introduction to human resource man- } \\
\text { agement }\end{array}$ \\
\hline Organization behavior & Global business context & Performance management \\
\hline
\end{tabular}

Legend: Plain - cluster subjects; light grey - core courses; dark grey - electives.

In an attempt to ascertain the suitability of the program, the following factors from an internal and external perspective have been considered (Chandra, et al., 2016) both from a university student's perspectives in the light of the requirements of the industry and at large from a skill and vocational perspective also in the Indian job market (Broeck \& Maertens, 2017).

Referencing the mismatching views of employers, education providers, and students, this study proposes the following internal and external factors to be integrated along with the curriculum for better employability.

\subsection{Mathematical model}

This study seeks to derive a mathematical model and possibly evaluate computerized process of hiring in which segment there is no verifiable record to attest that there exists a speedier hiring procedure. The study derives a multicollinear impact of web methodologies as the quantum of applications increases and suitable recruitment process is executed. The modeled variables consist of the corporate hiring mechanism process and study the desired outcome as a numerical method. It is asserted that the reduction in process of hiring quality might be the predominant impact that yields in poor output.

The study derives a simple numerical model in which applicant profiles are shortlisted along a homogeneous Poisson process. 
Two events occur, that is, profiles that meet the job profile and those that do not. As part of stage 1, the profile is screened and segregated into either of meets or does not meet criteria. Those that meet the required criteria are supposed to encompass an efficiency level $E_{i}$ that is derived from an estimated distribution with continuous efficiency function (CEF) R( ) with bounds at $[0,1]$.

The candidate's efficiency would be determined only subsequent to the interview process. The rate of receipt of applications is denoted as $\omega$. The expenses for screening each application are $e_{a}$. Applications not received in the Poisson process are proportional to the ones received as the homogeneous process. It can be derived that summative expenses for first stage is $e_{a} \omega$.

The processing duration of the application and time taken to roll out an offer or communicate a no-hire decision is taken as the applicant's intent to wait for the job offer. Each candidate $c$ has a waiting span $W_{c}$. The study takes that $W_{c}$ would be exponential with an average rate of $\lambda$ in that the possibility of the candidate accepting the job offer if made given the factor of interest and need based. Given these constructs, the model can adopt methods of Queueing Theory (QT). Receipt of applications is considered as arrivals while rejections and/or drop-outs can be termed as services.

$\vee\left(w_{1}\right)$ is the screened list of candidates who have submitted their profiles (arrival) in the first window of hiring time $h_{t}$, and $P\left(w_{1}\right)$ is the quantum of profiles interviewed (processed) and rejected in the same time window (departures) within $h_{t}$. The total candidates in queue for the first hiring cycle (window) would be $\vee\left(w_{1}\right)-P\left(w_{1}\right)$, which is the output of the adopted methodology for interviewing and the total quantum of potential applicants. Now, $H\left(w_{1}\right)=E \vee\left(w_{1}\right)-P\left(w_{1}\right)$ would be the total applicants in the employable set.

Subsequent to a fixed duration of time say $D_{t}$ post the employable set is arrived at, $E E\left(w_{1}\right)$ can be the estimated efficiency of the prime profiles available after $h_{t}$. The process also incurs a systematic expense $e_{a}$ for each candidate irrespective of hiring mandate and incurs an added cost of $e$ for those candidates who get recruited.

Adopting the linear quality structure with $r_{w}$ as the relative weight emphasized on the efficiency of the hired profile. The desired output would be

$$
\max _{h_{t}} a E E\left(w_{1}\right)-e_{a} \omega h_{t}-e_{a} H\left(w_{1}\right)
$$

where $e_{a}=1$ and $a$ is finitely scaled.

The expenses of hiring a profile in the first window of time and the associated cost rather than being appropriated over the entire time window, it is optimal to bound the time and expenses at $h_{t \max }$.

$\mathfrak{R} / \mathfrak{R} / \infty$ queue extends for $h_{t}$ starting at null, and during $h_{t}$, the probability that there are lapplicants in the $H\left(w_{1}\right)$ is given as

$$
p_{l}\left(h_{t}\right)=\frac{x\left(h_{t}\right)^{l}}{l !} e^{-x\left(h_{t}\right)}
$$

where

$$
x\left(h_{t}\right)=\left(1-e^{\lambda h_{t}}\right) \frac{\omega}{\lambda}
$$

Here we have derived that $H\left(w_{1}\right)=x\left(h_{t}\right)$. Let $e(l)$ be the highest from the entire sample of $l$, then

$$
E E\left(w_{1}\right)=\sum_{l=0}^{\infty} e(l) p_{l}\left(h_{t}\right)
$$

In the first phase, the study has hypothesized that the estimated distribution with CEF $R($ ) with bounds

$$
\begin{aligned}
\text { at }[0,1]: e(l) & =\frac{l}{l+1} \text { and } \\
E E\left(w_{1}\right) & =\sum_{l=0}^{\infty}\left(\frac{l}{l+1}\right) \frac{x\left(h_{t}\right)^{l}}{l !} e^{-x\left(h_{t}\right)}
\end{aligned}
$$

This is derived as

$$
E E\left(x\left(h_{t}\right)\right)=1-\frac{1}{x\left(h_{t}\right)}+\frac{e^{-x\left(h_{t}\right)}}{x\left(h_{t}\right)}
$$

This ascertains the improved probability of occurrence of $E E\left(w_{1}\right)$, that is, enhanced efficiency 
in quality of hiring, and as $x\left(h_{t}\right)$ is the constituent of increased $h_{t}, E E\left(w_{1}\right)$ improves as well. Hence, the extension of the window from first stage to second stage is plausible and well integrated with cost and efficiency even if the factor of rejection/drop outs increases proportionately as $x\left(h_{t}\right)$ moves to $\frac{\omega}{\lambda}$ as $h_{t}$ or the first hiring cycle is extended and bounded with the second hiring cycle.

On the same hand, expected quantum of candidates available for hiring in $H\left(w_{1}\right)$ will merge into $\frac{\omega}{\lambda}$.

The implication is that unbounded expenses $e_{a}$ will not yield in profitability as the receipt (arrival) screening (dispatch) from the queue becomes a constant. The derived value is maximum when equation 4, that is, $H\left(w_{1}\right)=x\left(h_{t}\right)$ can be read as the likelihood set of applicants for yielding the desired hiring quantum.

\subsection{Results discussion}

It is only the adoption of ICT that can yield desired results for all cases of increased exponential receipt of application (higher $\omega$ ) without iterating the rational balance of cost and time efficiency parameters. A good Object-Oriented Programming System (OOPS) can keep the expenses $e_{a}$ at a minimum.

Theoretically, placing $e_{a}=0$ (other variable time is considered as a constant) and referenced as a probability density function $\mathrm{x}^{*}$, higher $\omega$ will reduce processing time; however, the output would remain constant. While $w_{1} *$ lowers with $\omega$, probability of $x\left(\omega^{*}\right)$ remains a constant.

This asserts that if the hiring process is a subset of a fixed window of time and an assimilation that higher quantum of applications can improve output, it negates that quantum of applications is not a variable but a subset of the efficiency of hiring function adopted by the organization. If $e_{a}=0$, the best achievement for the organization is a reduced process of screening applications as part of the first stage.
Another optimization that can be achieved by adopting ICT is that candidates can explore other avenues for employment and this raises $\lambda$. This study asserts that ICT can stabilize $\omega$ as a constant and $x\left(h_{t}\right)$ as the pool of applicants at time $w_{1}$ in the complete set. The factor $\lambda$ can determine the time taken for the process to achieve optimality and negatively impacts the total quantum of applicants available in the set at $x\left(h_{t}\right)$. A high $\lambda$ is needed so as to achieve a rational quantum of applicants. In addition, a high $\lambda$ will ensure that unsuitable candidates would be separated at a faster rate and augments hiring quality. Interestingly, rational process time is not monotonic in $\lambda$ but decreases in $\omega$.

Adoption of ICT, on one hand, ameliorates the hiring process and, on the other hand, increases the queue of non-hires. Another unwanted outcome can be that as the monetary expenses are low for the screening of applications, arrival rates can be exponentially high and can attract lower quality of applications who can be less interested to stand the rigor of the screening process. The study through numerical experiments asserts that the ratio of increase in $\omega$ and $\lambda$ can be a constant; however, there will be limited tangible performance improvement. This derived stability is not a natural outcome but an output of the modeled assumptions.

This model theoretically adheres to a Poisson distribution arrival rate, rationalizes expenses for screening, and constructs an optimal pool of hirable resources. Adoption of ICT can guide decision making in terms of arriving at an optimal pool size from which desired results can be derived. In reality, as time lapses subsequent to the job posting, lesser applications arrive irrespective of last dates. In addition, a wider candidate database augmented by lower processing costs can dynamically alter the pool of applicants.

\subsection{Model testing}

Data referencing the received applications for EIGHT advertised positions (Data Analyst, Business Manager, Hostel Wardens (2 Nos.), Non-Teaching associate (2 Nos.), Deans Office associate and Mag- 
azine Coordinator) at our University were collected and the derived model was tested.

The method of beta distribution was used to test the model and its flexibility is assessed as follows. This testing would yield the expense assessment while executing the hiring process. The estimated receipt of profiles in the first stage is $h_{t} \geq 0$.

$$
E \vee\left(w_{1}\right)=k\left(1-e^{-\delta w_{1}}\right)
$$

And the arrival quantum would be

$$
\omega\left(h_{t}\right)=k \delta e^{-\delta w_{1}}
$$

These two functions, optimally categorize the data and parametric values of $\delta$ that range from 0.0681 to 0.1793 and fits $79.46 \%$ of allocations arriving within 8 ( $\delta=0.1793$ ) to 22 ( $\delta=0.0681$ ) from the date the job opening was publicized. The chosen parametric values are:

$$
k=6, \delta=0.0571, \frac{\lambda}{\delta}=0.0097, a=99, e_{a}=0.089
$$

Then $N_{\max }=4.594$ and $h_{i} N_{\max }=40.96$. Parametric iterations are reflected in Table 3.

Table 3. Testing of the model using live data for applications as per the Poisson process

(Source: Own study - computed using SPSS version 15, 2009)

$\lambda: k=11 \sim 12, e_{a}=0.0098$, and $\delta=11, \lambda=0.0057$

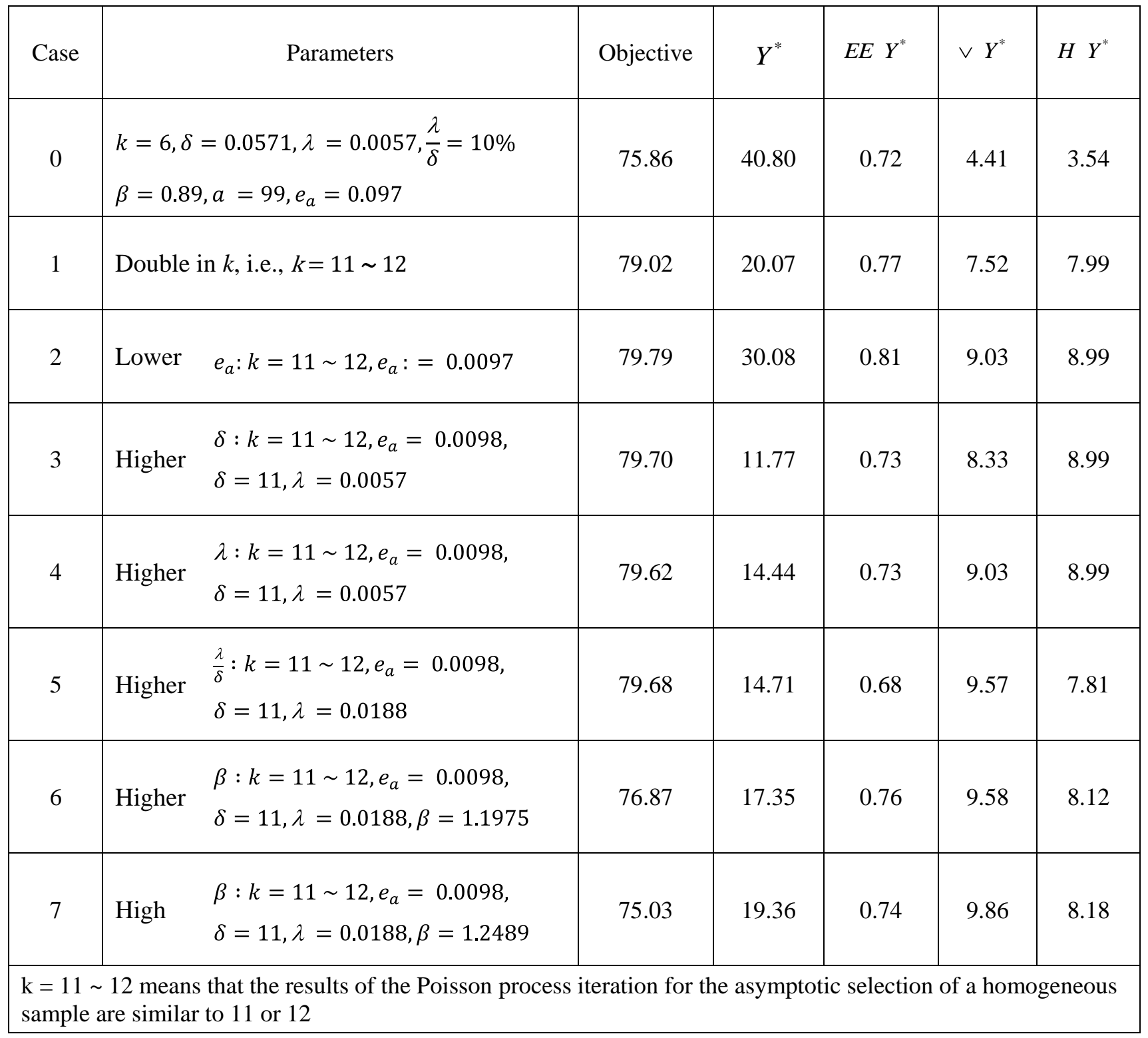


In Fig. 2 there is a schematic map for hiring.

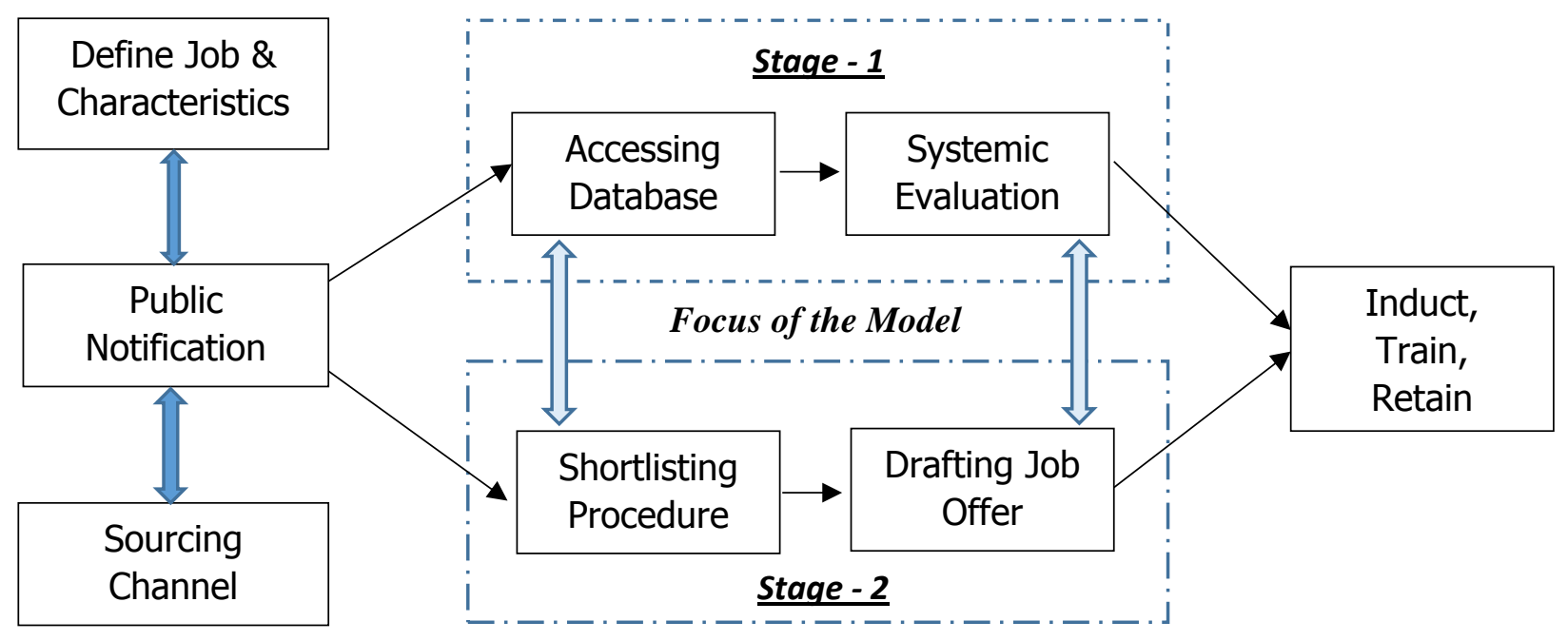

Figure 1. Schematic map for hiring

(Source: Own study - compiled from library and academic repositories)

A plausible ICT model for functional structure of the computer model using OOPS is used to determine the interdependent variables that form the essential outcomes of a unit of competency. Table 4 portrays a possible scope document framework. The framework is classified into associative elements and their functional performance criteria as the specifications document in the software development life cycle.

Table 4. The prime outlay of the scope and specification document

(Source: Own study - compiled from library and academic repositories)

\begin{tabular}{|l|l|}
\hline \multicolumn{1}{|c|}{ Elements } & \multicolumn{1}{c|}{ Performance Criteria } \\
\hline \multirow{4}{*}{ Design specifications } & Identify the flows and draft the schematic diagram with specifications \\
\cline { 2 - 3 } & Collaborations and sequencing diagrams with variables as specifications \\
\cline { 2 - 3 } & $\begin{array}{l}\text { Draft the interconnected activity and the state diagram from the same set } \\
\text { of specifications }\end{array}$ \\
\hline \multirow{5}{*}{ Design enhancement } & Measure and assimilate classes and their state of collaboration among classes \\
\cline { 2 - 3 } Targeting CMM ${ }^{1}$ Level 5 & Viable interconnectedness of state data and service classes \\
\cline { 2 - 3 } standards & Integrate Generalizations of classes \\
\cline { 2 - 3 } & Cointegrate classes with similar specializations \\
\cline { 2 - 3 } & Composition and aggregation principles for class refinement \\
\hline & Draft the layered static UML ${ }^{2}$ diagram \\
\cline { 2 - 3 } & Draft sequence and collaboration maps with interconnectedness as collaboration \\
\cline { 2 - 3 } & State diagrams and activity diagrams for final level of UML \\
\hline
\end{tabular}

${ }^{1}$ CMM - Capability Maturity Model

${ }^{2}$ UML - Unified Modeling Language 


\subsection{OOPS specifications to model integration of classes}

All designed classes to encompass vocational knowledge and desired technical skills.

Vocational skills: Communication skills for liaison

a) Technical skills to:

- Classes associated to yield in the required design,

- Abstraction completion to yield the desired class model,

- Domain knowledge overlap classes,

- Redefine hierarchies of inheritance to produce desired designs;

b) Required knowledge:
- Understanding of cohesion and coupling for metrics of design,

- Draft techniques for improvement,

- Prioritize principles of program design,

- Evaluate various methodologies as applicable for continuous improvement,

- Seamless design function enablement across the entire software development lifecycle.

\subsection{Draft action plan - implementation of ICT enabled learning}

The key success factors listed in Table 5 can be integrated into the ICT training program that can be executed to improve the employability of students in the global marketplace.

Table 5. A consolidate learning factors

(Source: Own study - compiled from library and academic repositories)

\begin{tabular}{|c|c|c|}
\hline \multicolumn{3}{|c|}{ Internal and External Factors of Learning } \\
\hline Students' cognitive ability & Peer effects & Representations \\
\hline Instructional quality & Advance organizers & Problem Solving \\
\hline Direct instruction & Computer-assisted instruction & Anticipate and Plan \\
\hline Remediation/feedback & Testing & Better Decision makers \\
\hline Students' disposition to learn & Instructional media & Classroom Climate \\
\hline Class environment & School Curriculum & Multidimensional Perspectives \\
\hline Challenge of Goals & Students' emotive characteristics & Sensitivity to Context \\
\hline Peer tutoring & Physical attributes of students & Feedback \& Monitoring Learning \\
\hline Mastery learning & Programmed instruction & Test Hypothesis \\
\hline Parent involvement & Ability grouping & Automaticity \\
\hline Homework & Audio-visual aids & Respect for Students \\
\hline Teacher Style & Individualization & Passion \\
\hline Questioning & Physical attributes & Set challenging tasks \\
\hline Team teaching & Behavioral objectives & Retention \\
\hline
\end{tabular}

\subsection{Approach and deployment - delivery model}

The methodologies that are convergent for all the three levels including electives are given in Fig. 2.
The aforesaid factors as per Fig. 2 need to be considered for analyzing the applicability of integrating the modus-operandi at a pan university level (Kumari, 2016). 


\begin{tabular}{ll}
\hline Lecture & Group Working \\
Seminar-Tutor Led & Simulation \\
Seminar-Student Led & Live Project \\
IT Lab sessions & Discussion Project \\
Case Studies & Role Play \\
\hline Workbook & Independent Learning \\
Peer Teaching & Guest Lectures \\
Exercise & Independent Study \\
Diagnostic test & Student Centered Tutorials \\
Student Centerd Learning & Interactive Seminars
\end{tabular}

Figure 2. A working model for ICT enablement

(Source: Own study - compiled from library and academic repositories)

Table 5 also indicates the action points that might need to be carried out before actual formalization and induction of this program into the curriculum of individual departments.

\section{The employer perspective}

In the era of 2016-2017, Companies go to different countries to outsource their goods and services. This means the journey is a dynamic variable and the aspirations of a plethora of aspirants is not a constant. As business evolves through the maze of competition and international sociocultural factors, honing the right skills becomes more important.

On one hand, for corporates, finding that one person who can deliver and help achieve goals (often lofty) becomes an arduous task (Ismail \& Kuppusamy, 2016).

On the other hand, for aspirants, exploring employment opportunities worth their knowledge and skills and being able to access the platform where they have been preparing for over a minimum of 5-6 years; once this interface occurs, it is a matter of skill demonstration and the need of the corporates for those skills and acceptance of the performance of the candidate and specific need requirement from the enterprise (Chakrabarti, 2016).

\subsection{The education-provider perspective}

It is not a determinant for educational institutions to ascertain the parameters of finding a job. Faculties of various departments (Ahmed, 2016) would not be well positioned to estimate or quantify the destinations that their students have embarked upon or are in the process to join their firm of choice. This study asserts that, possibly, if the choice of the student's destination is predetermined, a better delivery system could be designed and delivered if not tailor made (Woszczynski, et al., 2016) (Pandit, et al., 2016) in the trend of course credits and GPAs (Grade Point Average). In the days to come, if this methodology is not adopted, it could lead to a situation in which the student might find the degree or certificate that he or she has studied to secure would be of little value in terms of securing their coveted job (Prakash \& Rajaraman, 2016). As of now, this variation is not empirically tested and it is an adventure for each student studying to secure a general degree and embarks upon to secure that dream job, for which only time can answer if he or she has studied the right skills for that right job (Sandhu \& McQuarrie, 2016).

\subsection{Enrolment}

The aspect of enrolment is a deeper paradigm to be assessed using existing methodologies; it is almost boundless and highly dynamic in nature (Majumdar, 
2016). In India, it is simply a matter of access to higher education than the bent to pursue for a program of choice.

The higher education system is more general in nature, and after the tenured courses are completed, a student gets to seek for a job (Chakrabarti, 2016). The aspect of job-oriented programs, which deliver content that is relevant to the work profile, is catch- ing up in terms of industry-academic interfaces that is hugely popular these days, thanks to the knowledge diffusion facilitated by technology (Haraguchi, et al., 2017).

A summary table is established as an indicative measure to implement ICT framework (Pandit, et al., 2016), (Upadhayay \& Vrat, 2016) prior to each course design and curriculum setting (Fig. 3).

\begin{tabular}{|c|c|c|c|c|c|c|c|c|}
\hline DIMENSION & 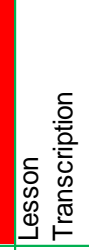 & 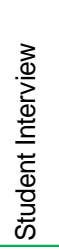 & 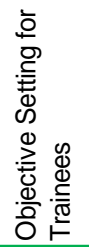 & ס & $\begin{array}{l}\text { 흘 } \\
\text { : } \\
\text { E्ञ } \\
\text { 오 }\end{array}$ & 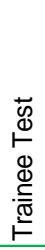 & 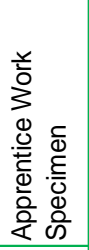 & 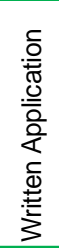 \\
\hline Implication of information & $v$ & $\checkmark$ & & & & & & \\
\hline Deeper Description & & $\checkmark$ & & $\checkmark$ & & & & \\
\hline Rational approach & $\checkmark$ & $\checkmark$ & & & & & & \\
\hline Unprepared teaching methods & & $\checkmark$ & & $\checkmark$ & & & & \\
\hline Challenge of Objectives & & $\checkmark$ & $\checkmark$ & r & & & & \\
\hline Classroom Climate & $\checkmark$ & & & & & $\checkmark$ & & \\
\hline Multidimensional Perception & $\checkmark$ & & & & & $\checkmark$ & & \\
\hline Responsiveness to Situation & $\checkmark$ & $\checkmark$ & & & & & & \\
\hline Monitoring Learning and Providing & $\checkmark$ & 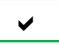 & & & & & & \\
\hline \multicolumn{9}{|l|}{ Response } \\
\hline Premise & & $\checkmark$ & & & & & & \\
\hline Acclaim grading criteria & $\checkmark$ & $\checkmark$ & & $\checkmark$ & & $\checkmark$ & & \\
\hline Committed Instructors & $\checkmark$ & & & & & $\checkmark$ & & \\
\hline Enthusiasm & & & & & & $\checkmark$ & $\checkmark$ & \\
\hline Aftermath & & & $\checkmark$ & & $\checkmark$ & & $\checkmark$ & $\checkmark$ \\
\hline
\end{tabular}

Figure 3. ICT enablers for pedagogy design

(Source: Own study - compiled from library and academic repositories)

\begin{tabular}{|c|c|c|c|c|}
\hline $\begin{array}{c}\text { Item } \\
\text { Number }\end{array}$ & Item Description & 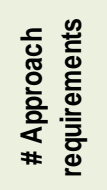 & 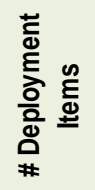 & 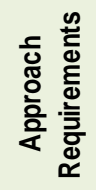 \\
\hline 1 & Implemeting New Programs and Requirements & & & \\
\hline 2 & Process Control & & & \\
\hline 3 & Forecasting, Staffing and Scheduling & & & \\
\hline 4 & Managing Transactions at Module level & & & \\
\hline 5 & Delivery Audit & & & \\
\hline 6 & Contingency Planning & & & \\
\hline 7 & Data Availability \& Updation Requirements & & & \\
\hline 8 & Defining Jobs, Induction and Hiring & & & \\
\hline 9 & Training and Development & & & \\
\hline 10 & Staff Performance and Management & & & \\
\hline 11 & Feedback Gathering process & & & \\
\hline 12 & Service Performance & & & \\
\hline 13 & Quality Performance and Process Level efficiency & & & \\
\hline 14 & Achieving Results and Asset efficiency & & & \\
\hline
\end{tabular}

Figure 4. Operational variables from an Indian context

(Source: Own study - compiled from library and academic repositories) 
Systematic delivery of training can assist curb the challenge of lower Indian employment levels. Multiple skills development missions and projects have been executed by Indian Government, and after a quick review (Sim, et al., 2017) of the major programs, Fig. 4 is presented to analyze the key variables for possible implementation in their program model (Kolay, 2016).

\section{Conclusion}

For a student, in the journey from education to employment, we have to specify the individual's strengths, limitations, choices, preferences, and key aspects that would keep our preferences flexible. Access to education is not a single-point agenda, or an alien aspect. The fundamental question is what is the chief objective of the education system in India? Given that education and systematic progression are fact paced, random, geographically spread across larger boundaries, sustained learning is a key driver. Focus on the skill to be honed, dedication to accepting the axioms of established theory, and continuous upkeep of technology, science, and social issues in the paradigm of real-time business can be a prime enabler for course curriculum and pedagogy of universities.

Evidence-based research, education needs to be holistic, and the objective of the educators coupled with the government system needs to be to facilitate the journey for seeks. There's a significant talent gap as there are people out of work, yet there are employers with job vacancy as they cannot find suitable candidates. The job training with systematic feedback of the mentor can be highly valuable, so that there is scope for improvement. Teacher's effectiveness should not be measured with only the marks of the students as a parameter, student's attendance, promotion, and so on should be taken into consideration. A system to assess teacher's effectiveness should be built so that the teacher knows in what areas he or she needs to improve. Long-duration vocational education of 'on-the-job' training can have better job prospects. The best of learners as evidenced by the previous 100 years of academic luminaries, Nobel Prize winners, Social Idols, Technocrats, Entrepreneurs, and others are achievers de- spite of hindrances within the education system. In the future, this study seeks that, parametric evaluation of student's aspirations vis-à-vis their objectives and aspirations be given a more systematic thought and design mechanisms to enable them embark on their journey to learning.

\section{$6 \quad$ References}

[1] Ahmed, T., 2016. Labour market outcome for formal vocational education and training in India: Safety net and beyond. IIMB Management Review, 28(2), pp.98-110.

[2] Bose, N., 2017. Raising Consumption Through India's National Rural Employment Guarantee Scheme. World Development, Vol. 96, pp.245263.

[3] Brewer, J.P., Hiller, J.G., Burke, S., Teegerstrom, T., 2016. A Primer: Extension, Indian Land Tenure, and Rangeland Limitations. Rangelands, 38(1), pp.16-22.

[4] Broeck, G.V.D. \& Maertens, M., 2017. Moving Up or Moving Out? Insights into Rural Development and Poverty Reduction in Senegal. World Development, Vol. 99, pp.95-109.

[5] Bussemakers, C., van Oosterhout, K., Kraaykamp, G., Spierings, N., 2017. Women's Worldwide Education-Employment Connection: A Multilevel Analysis of the Moderating Impact of Economic, Political, and Cultural Contexts. World Development, Vol. 99, pp.28-41.

[6] Chakrabarti, S.K., 2016. Industry Interface in Undergraduate Civil Engineering Education: Indian Context. Procedia Engineering, Vol. 161, pp.1982-1986.

[7] Chandra, R.M., Arora, L., Mehta, U.M., Asnaani, A., Radhakrishnan, R., 2016. Asian Indians in America: The influence of values and culture on mental health. Asian Journal of Psychiatry, Vol. 22, pp.202-209.

[8] Dhongde, S., 2017. Measuring Segregation of the Poor: Evidence from India. World Development, Vol. 89, pp.111-123.

[9] Fahey, N., Soni, A., Allison, J., Vankar, J., Prabhakaran, A., Moore Simas, T.A., Byatt, N., Phatak, A., O'Keefe, E., Nimbalkar, S., 2016. Education Mitigates the Relationship of Stress 
and Mental Disorders Among Rural Indian Women. Annals of Global Health, 82(5), pp.779-787.

[10] Fatma, M., Rahman, Z., 2016. The CSR's Influence on Customer Responses in Indian Banking Sector. Journal of Retailing and Consumer Services, Vol. 29, pp.49-57.

[11] Fernandez, A., Kambhampati, U.S., 2017. Shared Agency: The Dominant Spouse's Impact on Education Expenditure. World Development, Vol. 96, pp.182-197.

[12] Haraguchi, N., Cheng, C.F.C., Smeets, E., 2017. The Importance of Manufacturing in Economic Development. World Development, Vol. 93, pp.293-315.

[13] Ismail, A., Kuppusamy, K.S., 2016. Accessibility of Indian Universities' Home-pages: An Exploratory Study. Journal of King Saud University - Computer and Information Sciences, https://doi.org/10.1016/j.jksuci.2016.06. 006.

[14] Kolay, S., 2016. Cultural Heritage Preservation of Traditional Indian Art through Virtual Newmedia. Procedia - Social and Behavioral Sciences, Vol. 225, pp.309-320.

[15] Kumari, J., 2016. Public-private Partnerships in Education: An Analysis with Special Reference to Indian School Education System. International Journal of Educational Development, Vol. 47, pp.47-53.

[16] Landers, A.L., Danes, S.M., 2016. Forgotten Children: A Critical Review of the Reunification of American Indian Children in the Child Welfare System. Children and Youth Services Review, Vol. 71, pp.137-147.

[17] Majumdar, S.K., 2016. R\&D and the Overseas Earnings of Indian Firms. Technology in Society, Vol. 44, pp.104-111.
[18] Mehrotra, S., Parida, J.K., 2017. Why is the Labour Force Participation of Women Declining in India?. World Development, Vol. 98, pp.360380.

[19] Mishra, A., Verma, R., Kumar, A., Singh, A., Srivastava A., 2016. Significant Effect of Education \& Income on Cancer Control: Policy Consideration for Third World. Clinical Epidemiology and Global Health, Vol. 4, p.4.

[20] Pandit, A.K., Vibha, D., Srivastava, A.K., Shukla, G., Goyal, V., Behari, M., 2016. Complementary and Alternative Medicine in Indian Parkinson's Disease Patients. Journal of Traditional and Complementary Medicine, 6(4), pp.377-382.

[21] Prakash, K.B., Rajaraman, A., 2016. Mining of Bilingual Indian Web Documents. Procedia Computer Science, Vol. 89, pp.514-520.

[22] Sahai, A., 2016. Medical Education in India: Introspection, Challenges and Reforms A vision. Journal of the Anatomical Society of India, 65(2), pp.167-174.

[23] Sandhu, D., McQuarrie, F.A., 2016. An Innovative Model for Delivering Business Education in India. The International Journal of Management Education, 14(3), pp.301-309.

[24] Sim, A., Suryadarma, D., Suryahadi, A., 2017. The Consequences of Child Market Work on the Growth of Human Capital. World Development, Vol. 91, pp.144-155.

[25] Upadhayay, L., Vrat, P., 2016. Analysis of Impact of Industry-Academia Interaction on Quality of Technical Education: A System Dynamics Approach. Computers \& Industrial Engineering, Vol. 101, pp.313-324.

[26] Woszczynski, A.B., Dembla, P., Zafar, H., 2016. Gender-based Differences in Culture in the Indian IT workplace. International Journal of Information Management, 36(4), pp.507-519. 